\title{
The Slaughtening Causes with Dental and Gingival Lesions in Dairy Cows within Postmortem Period
}

\author{
Ibrahim Yurdakul, Ozge Ozdemir \& Ilker Sen
}

\begin{abstract}
Background: A regular and balanced feeding is essential for the animals in order to maintain their normal physiological function and be productive at the desired level. Digestion activities start with chewing in the mouth and the healthy dental arch is needed to perform a complete chewing function. Abnormal dental development and other dental pathologies impair digestive functions by negatively affecting chewing functions. The aim of the present study was to classified dental anomalies, dental degenerations, dental and gingival lesions seen in dairy cows and was aimed to reveal these lesions and depending on these disorders the reasons for slaughtering in dairy cows.

Materials, Methods \& Results: The material of this study consists of 600 dairy cows, being slaughtered for a year, and 170 dairy cows, detected dental anomalies, dental degenerations and dental-gingival lesions in the postmortem examination. Detailed macroscopic and radiological examinations of mandibles and maxillae of the dairy cows with dental and gingival lesions in postmortem examination were performed. The detailed information of the cases, such as: age, race, breeding, living region and slaughtering causes, etc. of dairy cows, suffering from dental lesions was recorded from slaughterhouse data access. In this study, 87 cases $(51.18 \%)$ of the determined dental lesions were defined as dental degeneration, 34 cases $(20 \%)$ as caries, 30 cases (17.64\%) as dental abnormalities in the formation and dental arch and 19 cases (11.18\%) as periodontal inflammation.

Discussion: In dairy cow breeding, there is a close relationship between production costs and business profitability and animal disease and fertility problems. Although the existence of negative effects of dental lesions directly on the digestive functions is known in dairy cattle breeding; there was no study about the state of dental diseases in dairy cow. In this respect, this research is quite important both for revealing the proportion of dental diseases seen in dairy cow and for drawing attention to the relationship between these diseases and the reasons for slaughtering of dairy cow. In this study, various dental anomalies, dental degenerations, dental and gingival lesions (28.33\%) were detected in 170 dairy cows, decreased milk production in 38 cases $(22.35 \%)$, infertility in 65 cases (38.24\%), gastrointestinal system diseases such as abomasal dislocation, constipation and indigestion in 38 cases (22.35\%) and foot diseases in 19 cases (11.18\%). Also, economic reasons were determined as slaughtering reasons in $10(5.88 \%)$ of the cases. The results of this research indicate that dental and gingival lesions may be regarded as preliminary results in the development of digestive system diseases, and then the various detailed clinical studies are needed to determine whether there is a relationship between digestive system diseases and dental diseases. As a result, this study first classified the dental lesions determined after slaughter in cattle and revealed the relationship between the reasons for slaughtering of dairy cows of the determined dental lesions. The results obtained in this study showed that dental anomalies, caries and periodontal inflammation effect significantly on the dairy cow fertility.
\end{abstract}

Keywords: dental anomaly, dental caries, dental inflammation, cow.

DOI: $10.22456 / 1679-9216.83156$ 
I. Yurdakul, O. Ozdemir \& I. Sen. 2018. The Slaughtening Causes with Dental and Gingival Lesions in Dairy Cows within

\section{INTRODUCTION}

Digestion activities start with chewing in the mouth and the most important of the nutritional activities is also chewing in cattle. The healthy dental arch is needed to perform a complete chewing function. Lesions, such as: abnormal dental development and structural alignment, dental corrosion, caries, periodontal inflammation, impair digestive functions by negatively affecting chewing functions. For this reason, the teeth have a great importance in terms of the digestive system in dairy cow [7].

There are a total of 32 teeth in cattle [6]. There are 8 teeth in the front part of the mandible, 6 of which are incisive and 2 of which are canine teeth [12]. There are 6 premolars (Pm) and 6 molar (M) teeth in both maxillae and mandible in cattle; a total of 24 teeth are available [6].

Dental caries; is a disease characterized by a brown or black colour change, manifested by the failure of hard tissues due to the presence of microorganisms and nutrients of decay-sensitive teeth [3].

Periodontal disease may progress to gingivitis along with subgingival plaque, chronic periodontitis after gingival sequestration and alveolar bone loss, or even teeth loss. Periodontal disease is seen in all teeth, but it is more severe in incisive teeth [5]. The covering of bacteria in gingiva and periodontal tissues causes progressive destruction of periodontal tissue, leading to clinical signs of periodontitis. As the inflammation progresses, septic pulpitis and tooth loss occur $[4,5,15,16]$.

The aim of the present study was to classified dental anomalies, dental degenerations, dental and gingival lesions seen in dairy cows and was aimed to reveal these lesions and depending on these disorders the reasons for slaughtering in dairy cows.

\section{MATERIALS AND METHODS}

\section{Study design}

The material of the study was consisted of 600 dairy cows, slaughtered during a year and 170 dairy cows that had dental anomaly, dental degenerations (abrasion and sharp elongation) dental and gingival lesion at postmortem examination. The detailed macroscopic and radiological examinations of the mandibles and maxillae of the dairy cows identified dental and gingival lesion in the postmortem examination were performed in the animal hospital. The detailed information of the cases, such as: age, race, breeding, living region and slaughtering causes, etc. of dairy cows, suffering from dental lesions was recorded from slaughterhouse data access.

\section{Macroscopic examinations}

The maxillae and mandibles of 170 dairy cows with dental and gingival lesion were examined for dental anomalies and gingival diseases, dental degenerations, caries and periodontal inflammation. The macroscopic photographs of the lesions of all cases were taken.

\section{Radiological examinations}

For the radiographic examination of mandibulae and maxillae, the $\mathrm{x}$-ray equipment (model PCMAX-100H) ${ }^{1}$ was used with a power of $100 \mathrm{~mA}$ and $100 \mathrm{kV}$. The dental anomalies, dental degenerations (abrasion and sharp elongation) dental and gingival lesions were determined in mandibulae L/M (Latero-Medial) and M/L (Medio-Lateral) positions, and maxillary radiographs were performed in $\mathrm{D} / \mathrm{V}$ (Dorso-Ventral) position.

\section{RESULTS}

Dental abrasions were detected in 76 of 170 cases and a significant rate was detected with aging (44.70\%). The tooth abrasion of the cases: 54 mandibular cases were seen in 12 cases and maxillary and 5 cases in 12 cases.

Eleven of the cases with dental deformities had significant and sharp elongation $(6.47 \%)$ in the maxillary teeth. In the 5 cases, the right and left maxillae Pm3 and M1 teeth were folded together and enlarged together. In 6 cases, only the right and left maxillary Pm3 teeth extended and prolonged.

Dental anomalies were determined that had oligodontia $(3.53 \%)$ in 6 cases, diastasis dentium $(13.53 \%)$ in 23 cases and hypodontia $(0.59 \%)$ in 1 case. The distribution of oligodontia, diastasis dentium and hypodontia in all cases determined in this research is shown in Table 1.

In all cases, $\mathrm{M}$ and $\mathrm{Pm}$ teeth were found to be intensely coloured with increasing age. The permanent colour changes were seen to have in caries determined cases (Figure 1). 
I. Yurdakul, O. Ozdemir \& I. Sen. 2018. The Slaughtening Causes with Dental and Gingival Lesions in Dairy Cows within

Table 1. Distribution of oligodontia, diastasis dentium and hypodontia in dairy cows.

\begin{tabular}{ccccccc}
\hline & \multicolumn{2}{c}{ Oligodontia } & \multicolumn{2}{c}{ Diastasis dentium } & \multicolumn{2}{c}{ Hypodontia } \\
\cline { 2 - 7 } Age & MN. & Max. & Mn. & Max. & Mn. & Max. \\
\hline 2 & 2 & - & - & - & - & - \\
3 & 1 & - & - & - & - & - \\
4 & 1 & 1 & 1 & 2 & - & - \\
5 & 1 & 1 & 2 & 2 & - & - \\
6 & 1 & 1 & 2 & 3 & 1 & 1 \\
8 & - & - & 7 & 5 & - & - \\
\hline
\end{tabular}

Mn: Mandibulae; Max: Maxillae.

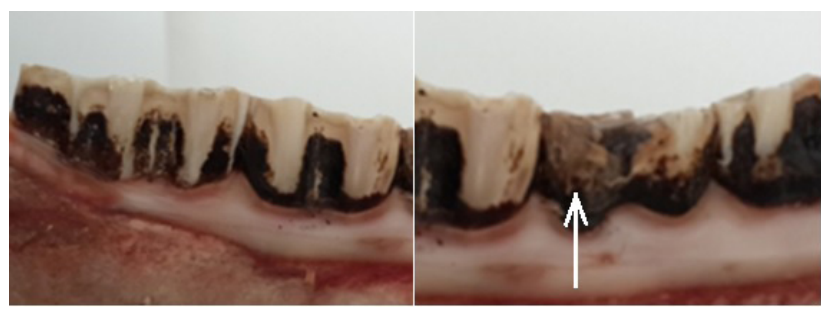

Figure 1. Dental colour changes in a caries lesion on the tooth of a dairy cow.

In this study 34 caries (20\%) were identified (Figures 2 and 3). The caries localization: 14 in mandible, 16 in maxillae, and 2 in both was determined. It was seen that 7 of the caries in mandible were right, 6 were localized on the left, and 3 were double-sided. Maxillar caries were found to be 10 in the right, 4 in the left maxilla, 4 in both. The distribution of the caries and periodontal inflammation in the cases is detailed in Table 2 and the localizations of the caries on the teeth in Table 3.

Periodontal inflammation (11.18\%) was detected in 19 cases: 10 in the mandibulae and 9 were identified in the maxillae. Periodontal inflammation was mostly seen

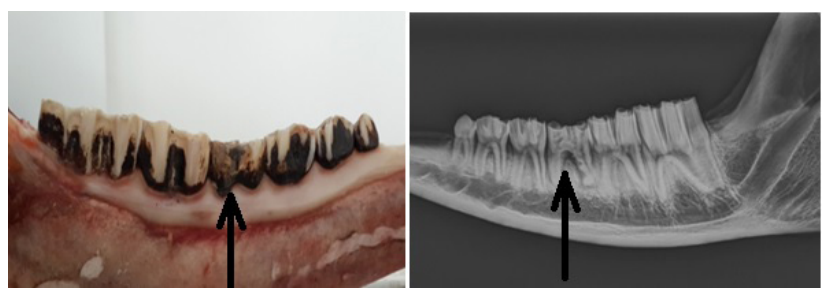

Figure 2. Caries on M1 in a 4-year-old dairy cow.

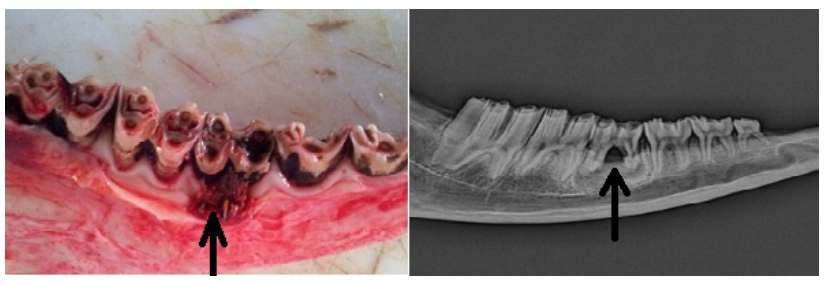

Figure 3. Periodontal inflammation and caries in 5-year-old dairy cow.
Table 2. Distrubition of caries and periodontal inflammation in dairy cows.

\begin{tabular}{|c|c|c|c|c|}
\hline Age & \multicolumn{2}{|c|}{ Caries } & \multicolumn{2}{|c|}{ Periodontal inflammation } \\
\hline & Mn. & Max. & Mn. & Max. \\
\hline 2 & 2 & 4 & 1 & 1 \\
\hline 3 & 2 & 3 & 1 & - \\
\hline 4 & 7 & 7 & 3 & 4 \\
\hline 5 & 4 & 4 & 4 & 3 \\
\hline 6 & 1 & - & 1 & 1 \\
\hline
\end{tabular}

Table 3. Localization of caries in the cases observed in dairy cows.

\begin{tabular}{ccccc} 
Carie & R Mn. & L Mn. & R Max. & L Max. \\
\hline Pm1 & - & - & - & - \\
Pm2 & 2 & - & - & - \\
Pm3 & - & - & 3 & 2 \\
M1 & 4 & 6 & 4 & 2 \\
M2 & 4 & 2 & 4 & 2 \\
M3 & - & 1 & 3 & 2 \\
\hline
\end{tabular}

Pm: Premolar tooth; M: Molar tooth; Mn: Mandibulae; Max: Maxillae; R: Right, L: Left.

in M1 and M2 (Figure 3). Periodontal inflammation was seen to form together with caries in 11 cases.

The various dental anomalies, dental degenerations, dental and gingival lesions $(28.33 \%)$ were detected in 170 dairy cows; The decreased milk production in 38 cases $(22.35 \%)$, infertility in 65 cases (38.24\%), gastrointestinal system diseases such as abomasal dislocation, constipation and indigestion in 38 cases $(22.35 \%)$, foot diseases in 19 cases $(11.18 \%)$ and economic reasons in 10 cases $(5.88 \%)$ were determined as slaughtering reasons of the cases. The slaughtering reasons for dental and gingival lesions identified in the cases are shown in Table 4.

\section{DISCUSSION}

There is a close relationship between production costs and profitability and animal diseases and fertility problems in dairy farming. Controlling the milk production and unit production costs with low profit margins is the most important factor in management's success.

The reported that average annual economic loss due to metritis, mastitis, hypocalcemia and foot diseases to be 65 \$ per cow per year and it was indi- 
I. Yurdakul, O. Ozdemir \& I. Sen. 2018. The Slaughtening Causes with Dental and Gingival Lesions in Dairy Cows within

Table 4. The Slaughtering reasons for the determined dental and gingival lesions in the cases observed in dairy cows.

\begin{tabular}{ccccccc}
\hline \multirow{2}{*}{$\begin{array}{c}\text { Slaughtering } \\
\text { cause }\end{array}$} & Anomaly & Carie & Abrasion & Elongation & $\begin{array}{c}\text { Periodontal } \\
\text { inflammation }\end{array}$ & $\begin{array}{c}\text { Cases } \\
\text { (n) }\end{array}$ \\
\cline { 2 - 6 } $\begin{array}{c}\text { Decreased milk } \\
\text { production }\end{array}$ & 4 & 12 & 3 & 3 & 16 & 38 \\
$\quad \begin{array}{l}\text { Infertility } \\
\text { Digestive }\end{array}$ & 10 & 14 & 13 & 10 & 18 & 65 \\
$\begin{array}{c}\text { systemdiseases } \\
\text { Food Diseases }\end{array}$ & - & 16 & 4 & 1 & 17 & 38 \\
Economic & 1 & 4 & 5 & 2 & 5 & 19 \\
\hline
\end{tabular}

cated that $75 \%$ of this loss was preventable loss [18]. Although the existence of negative effects of dental lesions directly on the digestive functions is known in dairy cattle breeding; there was no study about the state of dental diseases in dairy cow. In this respect, this research is quite important both for revealing the proportion of dental diseases seen in dairy cow and for drawing attention to the relationship between these diseases and the reasons for slaughtering of dairy cow.

During physiological chewing, the chewing surfaces of the mandibular and maxillary teeth are regularly abraded via friction. However, the crops that are too rooted cannot pull off the animal and have to strip it during the grazing in improved pasture and due to these repetitive movements, the teeth are always sustain to excessive abrasion. For this reason, sharpedged abrasion is seen commonly in ruminants. Due to the dental disorders, sharp-edged teeth can cause chewing difficulty by injuring the tongues, buccas or both. In addition, feeds are collected between buccas and teeth during feeding $[13,19]$. Dental abrasions were found to increase with age with a total of 76 cases. Abrasions were detected in 54 lesions in the mandibulae, in 12 lesions maxillae and in 5 lesions both mandibulae and maxillae lesions were detected. It was defined that dental abrasion was particularly intense in mandibular Pm3 and M1 teeth. In addition, only 11 cases in maxillae Pm3 and M1 teeth were observed to have an abnormal sharp elongation.

Many researchers $[8,13,14]$ indicate that, depending on these dental degenerations occurred on the teeth, the grass or feed can gather between the teeth and the buccas during feeding, thus seriously prevent- ing chewing. Inadequate chewing function or irregular abrasions on the teeth causes the animals not to benefit from the feed at the desired levels and results in loss of yield. In this study, it has been determined that loss of yield will be formed due to the dental degenerations on teeth and that this loss of yield should be counted among the reasons for slaughtering of dairy cow.

Provided that the teeth are not to be formed, it is named as anodontia, and this is usually associated with skin anomalies in the calves. It is called pseudoanodontia when the teeth normally developing in the embryonic term are embedded in the alveolar bone [10]. Hypodontia is failure of some teeth in terms of size. Oligodontia is the number of missing teeth. Being formed more than normal number of teeth is called polydontia and heterotopic polydontia is an extra tooth formation out of the dental arch. After the eruption of permanent teeth, the excessive number of teeth is called pseudopolidontia due to the non-dropping of the primary teeth $[2,4,9,10]$. Oligodontia was determined as 2 teeth in maxillae and 1 mandibulae in 2 cases, 2 teeth in maxillae in a case and 1 mandibulae in a case, 2 teeth in mandibulae in a case and 1 mandible in 2 cases, i.e. totally in 6 cases. No relationship between oligodontia and age was established and it is determined that loss of one or two teeth formed in mandibulae and maxillae cannot lead to digestive system problems with insufficient number of cases examined.

Abnormal abrasions on teeth are seen more commonly in oligodontia, in interstices between teeth (diastasis dentium), and in tooth decay. These subnormal abrasions cause extreme prolongation of the tooth, leading to injury to the gingiva or buccal mucosa on 
the contralateral side $[10,19]$. In this study, in 23 cases, diastasis dentium was determined and 11 of these cases were shaped in mandibulae, 11 in maxillae and 1 in both mandibulae and maxillae. Diastasis dentium when the age of the cases is considered; it was determined that the incidence of diastasis dentium cases increased with age.

Caries is seen in all teeth, especially premolars and molars. The caries formation is occured in maxillary teeth more common than mandibular teeth $[10,14]$. It has been reported that caries in dogs is seen in 5-35\% of cases and M1-M2 mandibulae and M1 maxillae were more affected [3]. Six hundred dairy cows examined in this study; caries $(5.67 \%)$ were identified in 34 cases and localization of caries was found to be intensively shaped in M1 and M2 of mandibulae and maxillae. This situation was interpreted as the absence of a significant difference in mandibula/maxilla distribution in caries' dairy cows. Considering of the causes of slaughtering in dairy cows, 16 cases of caries with complaint of digestive system diseases indicate that there is a relationship between dental caries and digestive system diseases. The fact that caries has been determined in dairy cows, which slaughter due to decreased milk production and infertility complaints, shows that caries can lead to significant loss in dairy cow farming.

Periodontal disease may progress to gingivitis along with subgingival plaque, chronic periodontitis after gingival sequestration and alveolar bone loss, or even teeth loss [5]. Periodontal inflammation has been reported to be associated with systemic diseases such as cardiovascular complications, rheumatoid arthritis and unwanted pregnancy outcomes [11]. In this study, tooth anomalies, dental and gingival lesions were identified with periodontal inflammation in 19 cases. When considering the slaughtering reasons of dairy cow, determined periodontal inflammation, the systemic diseases such as; infertility, decreased milk production and digestive system disease are seen primarily. This view suggests that periodontal inflammation is directly related to systemic diseases.
The most common dental problems in cattle has been reported as dental tartar and periodontal inflammation [17]. In this study, 34 cases of caries and 19 cases of periodontal inflammation support the opinion of the related researcher.

It is reported that the most common thirddegree health problems in large animals in the United States are dental problems [3]. In a study conducted in Turkey was reported that dental disorders in horses has been reported as $28.4 \%$ [8]. In this study, tooth and gingival diseases were determined in 170 (28.33\%) of 600 milk cows examined after slaughter. It has been concluded that these dental diseases are an important health problem in cows.

\section{CONCLUSIONS}

The results of this research indicate that dental and gingival lesions may be regarded as preliminary results in the development of digestive system diseases, and then the various detailed clinical studies are needed to determine whether there is a relationship between digestive system diseases and dental diseases.

As a result, this study first classified the dental lesions determined after slaughter in cattle and revealed the relationship between the reasons for slaughtering of dairy cows of the determined dental lesions. The results obtained in this study showed that dental anomalies, caries and periodontal inflammation effect significantly on the dairy cow fertility.

\section{MANUFACTURER \\ ${ }^{1}$ Poscom Co., Ltd. Goyang, South Korea.}

Funding. This research was financially supported by the Scientific Research Council of Cumhuriyet University (Project No: V-058).

Declaration of interest. The authors report no conflicts of interest. The authors alone are responsible for the content and writing of the paper.

\section{REFERENCES}

1 Boyd W. 1976. Dental pathology. In: Body W. (Ed). A Textbook of Pathology Structure and Function in Disease. Philadelphia: Lea \& Febiger, pp.1429-1441.

2 Dixon P.M. \& Dacre I. 2005. A review of equine dental disorders. The Veterinary Journal. 169(2): 165-187.

3 Figurová M., Ledecky V. \& Stvrtına S. 2006. Evaluation of marginal microgaps of two glass-ionomer cements (GIC) in dogs and sheep in vivo. Journal Acta Veterinaria Brno. 75(3): 403-410.

4 Gorgul O.S., Yavru N., Atalan G., Demirkan I., Kilic N., Sarierler M., Tas A., Altug., M.E., Cecen G., Kibar M., 
Pekcan Z., Salci H. \& Kurum B. 2012. Veteriner Özel Cerrahi. Malatya: Medipress, pp.89-157

5 Greene S.K. \& Basile T.P. 2002. Recognition and treatment of equine periodontal disease. American Association Equine Practitioners. 48: 463-466.

6 Hall J.B. \& Silver S. 2009. Nutrition and feeding of the cow-calf herd: Digestive system of the cow. Virginia Cooperative Extension Publication and Educational Resources. 400: 400-410.

7 Kandemir L. \& Sindak N. 2009. Evaluation of equine dental disease and disorders in Sanliurfa Region. Van Veterinary Journal. 20(2): 39-43.

8 Kilıc S., Canpolat I., Bulut S. \& Hayat A. 1997. A survey carried out on some dental disorders of 95 horses. Turkish Journal Veterinary Surgery. 3(2): 42-47.

9 Metin N. 2011. Veteriner Patoloji. Aydın: Tuna, 25p.

10 Milli Ü.H. \& Hazıroglu R. 1997. Veteriner Patoloji. Malatya: Medipress, pp.28-34.

11 Oz H.S. \& Puleo D.A. 2011. Animal models for periodontal disease. Journal of Biomedicine and Biotechnology. 2011: 1-8.

12 Pace J.E. \& Wakeman D.L. 2003. Determining the age of cattle by their teeth. Animal Science Department, Institute of Food and Agricultural Sciences (IFAS), University of Florida, USA. pp.1-4. Available at $<$ http://edis.ifas.ufl.edu $>$ [Accessed online in June 2017].

13Saglam K. 2012. Equine dental diseases. Van Veterinary Journal. 23(2): 111-118.

14Samsar E. \& Akın F. 2006. Veteriner Özel Cerrrahi. Malatya: Medipress, pp.102-125.

15Schenkein H. 1999. The pathogenesis of periodontal diseases. Journal of Periodontology. 70(4): 457-470.

16 Struillou X., Boutigny H., Soueidan A. \& Layrolle P. 2010. Experimental animal models in periodontology: A review. The Open Dentistry Journal. 4: 37-47.

17 Tuns S. \& David C. 2010. Oral bacterial flora in cattle with dental calculus and periodontitis (preliminary results). Lucrărı Ştıntıfice Medicınă Veterinară. 43(1): 299-303.

18 Yalcin C. 2008. Dairy cattle operations economic open health and safety disease management. Aktüel. 79(1): 24-30.

19 Yucel R. 1992. Veteriner Özel Cerrahi. Kocaeli: Pethask, pp.56-64. 